\title{
Produção de livros didáticos no mestrado profissional de História: relato de experiência a partir de uma disciplina da UFRB ${ }^{1}$
} School Textbooks Production in History Professional Master: experience report from a UFRB's module

Leandro Antonio de Almeida*

\section{RESUmo}

Este trabalho reflete sobre a produção de materiais didáticos no Mestrado Profissional de História. Apresentaremos essa modalidade de pós-graduação stricto sensu que se expandiu na área de História nos últimos anos e, depois, trataremos dos desafios do tema mediante uma experiência de produção em uma disciplina intitulada "Metodologia da Pesquisa e da Produção de Materiais Didáticos". Nela solicitava-se aos mestrandos material didático, acompanhado de um guia para o professor, em qualquer formato e suporte, sobre um dos temas de pesquisa do programa. A maioria dos alunos optou por trabalhar com livros paradidáticos, apresentados em formato digital (PDF). Durante a escolha e produção foram utilizados saberes acadêmicos, pedagógicos e práticos, mobilizados conforme o contexto dos alunos e os objetivos formativos. Os relatórios dos mestrandos mostraram a pouca familiaridade com a linguagem voltada

\section{Abstract}

The aim of this paper is to discuss the production of teaching materials in the History Professional Master. First we introduce this type of stricto sensu postgraduate mode that has expanded in the history Field in recent years. Then we treat the theme challenges through production experience in a course entitled "Research and Production Methodology of Teaching Materials". It was requested to students any teaching material, accompanied by a teacher's guide, in any format and support, about any of the master program research topics. The students' choice was mostly produce thematic teaching books, presented in digital format (PDF). While choosing and making the books they used scholar, didactic and practical knowledges, according to the pupil context and formative objectives. The main problems identified in the student's reports were unfamiliarity with the language oriented to basic education pupils

\footnotetext{
* Doutor em História Social pela Universidade de São Paulo (USP), professor do Centro de Artes, Humanidades e Letras (CAHL) da Universidade Federal do Recôncavo da Bahia (UFRB). Cachoeira, BA, Brasil. leandroaalmeida@hotmail.com
} 
aos alunos da educação básica e com os saberes de edição e diagramação dos livros. Por fim, a produção de materiais didáticos de maneira interdisciplinar é um desafio para os mestrandos. Palavras-chave: produção de livro didático; mestrado profissional; formação de professores. and knowledge about books editing and layout. At last, we discuss the challenge of a Professional Master in History to produce teaching materials in an interdisciplinary way.

Keywords: school textbook making; Professional Master; teacher formation.

\section{Mestrados Profissionais em História no Brasil}

Prevista no parecer de Newton Sucupira de 1965, que estrutura o sistema de pós-graduação no Brasil, a legislação sobre mestrado profissional data da segunda metade da década de 1990. Reconhecido em 1998 e regulamentado pela Coordenação de Aperfeiçoamento de Pessoal em Nível Superior (Capes) em 2009, o Mestrado Profissional é uma modalidade de pós-graduação stricto sensu que possibilita "a capacitação de pessoal para a prática profissional avançada e transformadora de procedimentos e processos aplicados, por meio da incorporação do método científico, habilitando o profissional para atuar em atividades técnico-científicas e de inovação" (Capes, 2009, parágrafo $3^{\circ}$ ). Atualmente a última etapa da educação profissional no país, espera-se de tais cursos maior intercâmbio com a sociedade em geral, e com o setor produtivo em particular, por meio do conhecimento aplicável à solução de problemas. Daí os mestrados profissionais terem duas diferenças em relação aos mestrados acadêmicos: a possibilidade de contar com não doutores de reconhecido mérito profissional em seu corpo docente e, principalmente, o trabalho final ser apresentado em modalidades distintas da dissertação.

$\mathrm{Na}$ área de História, o surgimento de mestrados profissionais foi tardio. Até dezembro de 2012 eram apenas dois e, atualmente, há menos de uma dezena de programas funcionando no país. O mais antigo, ativo desde 2003, é o de História, Política e Bens Culturais da Fundação Getúlio Vargas (FGV). Depois dele, com exceção da comunitária Universidade Caxias do Sul (UCS), os outros mestrados foram criados em instituições públicas de ensino superior, no Rio Grande do Sul - na Universidade Federal do Rio Grande (Furg), em Minas Gerais - Universidade Federal de Viçosa (UFV) e Universidade Federal 
de Alfenas (Unifal), Goiás - Universidade Federal de Goiás (UFG-Catalão), Maranhão - Universidade Estadual do Maranhão (Uema), e Bahia - Universidade Federal do Recôncavo da Bahia (UFRB). Fomentado pela Capes, há ainda o ProfHistória que, coordenado pela Universidade Federal do Rio de Janeiro (UFRJ), integra dezenas de universidades em uma rede de professores mestrandos pelo Brasil (Capes, SNPG, área de História e Interdisciplinar, 2015).

No Documento de Área de História (2013, p.16), a coordenação da Capes reconhece como áreas de atuação do historiador passíveis de proposição de cursos profissionais o patrimônio histórico, a arquivística, serviços de museu e documentação, museologia e museografia, artes, turismo, organização de informações históricas, consultoria e pareceres históricos, e ensino e material didático. Os Mestrados Profissionais mencionados cobrem direta ou indiretamente tais áreas, com concentração maior das propostas em Ensino de História, considerado um problema crucial para o país. A esmagadora maioria dos programas (5) dedica-se à docência, campo profissional majoritário para atuação dos historiadores. A presença do ensino também ocorre em programas com outras áreas da História, como é o caso da Universidade Federal de Viçosa, com uma linha sobre educação e patrimônio. O mesmo acontece em programas com foco temático, como a Universidade Federal de Alfenas (História Ibérica) e a Universidade Federal do Recôncavo da Bahia (História da África, Diáspora e Povos Indígenas), com disciplinas e pesquisas ligadas à educação e ensino de História.

Apesar da incipiência dos programas recém-formados, os impactos na área já começaram a ocorrer. No âmbito da Capes, além do fomento de um programa como o ProfHistória, criou-se uma coordenação adjunta específica para Mestrados Profissionais e uma ficha de avaliação que considerem suas especificidades. A Associação Nacional de História (Anpuh), além de apoiar o fomento de tal modalidade, tem acolhido nos fóruns demandas dos poucos programas, como a questão do financiamento e a especificidade da avaliação. Neste particular, quatro fóruns dos coordenadores de Pós-Graduação promovidos pela entidade, realizados em 2014 (Belo Horizonte e Maceió) e 2015 (Curitiba e Salvador), contaram com comissões específicas para elaborar critérios de avaliação da produção didática e produção técnica em História. As propostas foram pensadas analogamente aos Qualis atualmente vigentes para livros e periódicos, e após as discussões e contribuições o Fórum pretende 
remetê-las para apreciação das comissões da Capes, visando sua incorporação em avaliações futuras. Independentemente da sua adoção, a formulação e discussão de tais critérios sobre uma dimensão importante da produção dos Mestrados Profissionais podem se tornar referenciais para toda a área, a exemplo do que atualmente ocorre com outros programas governamentais como o Programa Nacional do Livro Didático (PNLD).

Como a maioria dos programas foi criado após 2013, talvez seja necessário tempo para se analisar o conjunto da produção de dissertações e outros formatos do Trabalho Final de Curso, apesar de já ser possível vislumbrar resultados parciais dos mestrandos, publicados em artigos e anais de eventos pelo país. Por exemplo, nos Anais do XXVIII Simpósio Nacional de História (Anpuh, 2015) é possível encontrar 17 trabalhos nos quais os autores se identificam como alunos de Programas dos Mestrados Profissionais. Além deles, em dois resumos de comunicações, não publicados nos anais, há alunos com a mesma identificação. Estão assim distribuídos: UFRB (3), ProfHistória (diversas universidades - 5 artigos e 2 resumos), UFG Catalão (4), Furg (2), UCS (1), UFV (1) e Uema (1).

Mesmo funcionando na fase inicial, iniciativas de reflexão geral já foram tomadas pelos Programas nos encontros de Mestrados Profissionais de História, que ocorreram em 2014 em Alfenas, MG (Unifal, 2014) e em 2015 em Catalão, GO (UFG/Catalão, 2015). Compostas por coordenadores e integrantes da Capes e da Anpuh, as mesas-redondas discutiram as ações dos Programas, seu papel para formação dos professores, interface com a sociedade nas dimensões de memória e patrimônio, os desafios de consolidação dessa modalidade na área e também os formatos dos trabalhos finais de curso. Durante o último evento estabeleceu-se como sede do III Encontro, a ocorrer no final de 2016, a Fundação Getúlio Vargas, no Rio de Janeiro. A previsão é que ele conte com a apresentação de trabalhos finais não dissertativos defendidos nos programas, o que permitirá avaliação mais precisa dos rumos dessa produção no Brasil.

\section{Mestrados Profissionais, materiais DIDÁTICOS E FORMAÇÃO DOS PROFESSORES}

Além dos encontros, já é possível ter acesso a reflexões acadêmicas sobre o tema. Registramos um resumo de apresentação em evento e três artigos em revistas especializadas. Focado na política de fomento a essa modalidade, o 
primeiro foi apresentado no Simpósio Nacional de História (Anpuh, 2015) por Cláudia Regina Amaral Afonso, tendo como título "O Mestrado Profissional em Ensino de História, entre a práxis e o pragmatismo: o papel indutivo da Capes". Já o artigo escrito por Júlia Matos e Adriana Senna aborda o papel do "Mestrado Profissional de História e a formação docente para a pesquisa" a partir da crítica da separação entre os campos de pesquisa e ensino, visando sua superação com a formação para pesquisa-docência. Os mestrados profissionais na área de Ensino de História, segundo as autoras, surgem para suprir essa necessidade de formação continuada, tendo "como função a capacitação dos docentes para a pesquisa em sua área, com foco principal em sua própria prática" e também para "desenvolver pesquisas voltadas à análise do ensino de História como aparelho cultural, social e político, capaz de interferir na formação da memória e das identidades coletivas" (Matos; Senna, 2013, p.217-218, grifos das autoras).

Mais recente que o anterior, o segundo artigo também versa sobre o perfil do aluno. Intitula-se "A História e seu ensino na concepção dos professores/ mestrandos em História" e trata do tema a partir da aplicação de um questionário a uma turma de 15 mestrandos do ProfHistória, tendo como base as reflexões de Jörn Rüsen. Os questionários apontam como as leituras e debates do primeiro semestre já modificaram a concepção dos professores, no sentido de superar a distância entre História acadêmica e escolar, processos que se espera aprofundar nas etapas subsequentes do Mestrado. Em primeiro lugar, "os mestrandos conseguem notar ... que é possível aproximar a História ciência e o Ensino de História, e, essa aproximação abre muitas possibilidades de se ousar e de se experimentar novas metodologias e novas abordagens para se pensar e se ensinar história”. Segundo, que sejam capazes de produzir algo novo, superando a ideia de passividade e transmissão de conteúdos. Terceiro, como função social, contribuem para formação dos estudantes da educação básica a partir da noção de processo histórico, contra a perspectiva que mantém e naturaliza estruturas sociais excludentes, mesmo contra a carga horária reduzida e as condições nem sempre favoráveis (Fernandes et al., 2015, p.111-114).

O último artigo debruça-se sobre resultados mediante algumas produções. Escrito por Roberto Radünz e intitulado "Mestrado Profissional em História: o desafio do Trabalho Final de Conclusão de Curso", avalia o potencial das 
novas modalidades a partir dos trabalhos de qualificação das linhas de pesquisa na Universidade Caxias do Sul. Além de reflexões historiográficas e sobre ensino, aparecem como produtos metodologias de ensino, oficinas, manual de introdução à história da Arte para o ensino superior, material didático com sugestões de ensino por meio de música e quadrinhos, materiais impressos e de mídia sobre história local para Educação Básica, material audiovisuais e jogo de tabuleiro com base em documentos (Radünz, 2015).

Os artigos mencionados tratam das contribuições dessa modalidade de pós-graduação stricto sensu ao campo da História, tendo como foco a área de Ensino. Ao apresentar concretamente a imbricação entre abordagens temáticas e diversidade de suportes, o artigo de Radünz permite vislumbrar as possibilidades abertas pelos mestrados profissionais, com potencial de "se constituir nos novos polos de inovação da produção em história no Brasil” (Grinberg, 2014). A frente de pesquisa aplicada em História alarga possibilidades de reflexão e direção de produção do conhecimento, pautado nos questionamentos e visando solução de problemas oriundos da experiência e do campo de trabalho dos mestrandos, na maior parte professores. Ao mesmo tempo, o processo de investigação acadêmica favorece percepção renovada do ensino e da docência, como apontam os artigos de Fernandes et al. (2015) e Matos e Senna (2013), ao ressaltar a especificidade do saber histórico escolar e dos saberes docentes, sua relação com a pesquisa e a importância da reflexão sobre a prática. Os mestrados profissionais tornam-se, assim, um espaço a mais para formação continuada, em nível de pós-graduação, e possibilitam que se aprofunde o trabalho inicial realizado nos cursos de licenciatura em História.

Neste artigo partiremos de um ângulo mais restrito para analisar tais possibilidades. Nosso foco será a reflexão sobre a formação de professores a partir da produção de materiais didáticos. Aqui trataremos dos materiais didáticos definidos no sentido de "suportes informativos", que "correspondem a todo discurso com intenção de comunicar elementos do saber das disciplinas escolares", os quais podem integrar em seu interior aquela outra categoria que Circe Bittencourt (2008, p.296) denominou "documentos", diferindo deles pela sua intenção didática. Por essa intenção, é possível generalizar para os demais suportes as características complexas dos livros didáticos de História, já que veiculam conhecimentos históricos escolares, em conexão com os saberes teóricos, conceituais e temáticos da historiografia; conhecimentos pedagógicos, 
ao propor mecanismos de aprendizagem; valores e ideologias; e, por fim, são um produto "fabricado por técnicos que determinam seus aspectos materiais" (Bittencourt, 2008, p.301-302). Tal característica foi aprofundada por Kazumi Munakata, que analisou as práticas de fabricação dos livros didáticos pelas editoras, cujas equipes com funções e saberes diversos interferem na materialidade - e nos sentidos - do produto final (Munakata, 1997).

Cabe então perguntar como os professores lidam com a elaboração de materiais didáticos. A partir dos trabalhos de Tardif (2002) e Monteiro (2007), que estudam o contexto da sala de aula, podemos indagar como nesse processo se articulam os saberes docentes - saberes das disciplinas de referência, saberes pedagógicos, saberes curriculares, os saberes de manipulação das linguagens (visual e escrita), os saberes da prática ou da experiência e, no caso das equipes, os interpessoais. Logo, quais saberes mobilizam para lidar com as múltiplas dimensões e com a complexidade do processo de produção didática? Daqui por diante vamos abordar essa questão do "professor como produtor" a partir de uma disciplina de um mestrado profissional da área de História situado no Recôncavo da Bahia. Apresentaremos a seguir a disciplina "Metodologia da Pesquisa e da Produção de Materiais Didáticos", depois analisaremos os resultados parciais a partir dos relatórios finais para, enfim, discutir suas implicações para a pós-graduação profissional em História.

\section{ApresentaÇão DA DisCiPLINA DE PÓS-GRADUAÇÃo}

O Mestrado Profissional em História da África, da Diáspora e dos Povos Indígenas da UFRB teve seu primeiro processo seletivo no segundo semestre de 2013 e está em pleno funcionamento desde o início de 2014. Como o próprio título expressa, o programa tem por objetivo formar profissionais capazes de desenvolver plenamente a Lei 11.645 mediante dissertações, materiais didáticos e laudos técnicos, entre outros produtos. Têm como mestrandos professores da educação básica, licenciados e pedagogos, muitos dos quais vivenciam a questão racial nas salas de aula da Bahia. A disciplina Metodologia da Pesquisa e da Produção de Materiais Didáticos é obrigatória na matriz curricular, ofertada no $2^{\circ}$ semestre de 2014 com uma carga de 68 horas. Sua ementa prevê este conteúdo: 
Ensino de História: da formação das identidades à construção do conhecimento. A pesquisa em materiais didáticos e linguagens no ensino de história. Papel da pesquisa na História escolar e na formação do professor. O livro didático de história. Uso de documentos na aula de história. Materiais didáticos de história: análise e produção. (UFRB, 2014)

Enquanto docente ministrante, colocamo-nos um desafio: estabelecemos que ela deveria contemplar o aspecto profissional ou técnico próprio do mestrado profissional. O desafio se desdobrou em dois objetivos complementares: possibilitar ao mestrando vivenciar a produção de um material didático de história e, nesse processo, refletir criticamente sobre o tema. Para aqueles pesquisadores e professores que fossem apresentar trabalhos finais não didáticos como dissertação e relatório, o curso possibilitaria uma experiência inédita, já que, de 15 matriculados, apenas uma mestranda tinha experiência em produção comercial de livros didáticos, e outro já havia editado às próprias expensas um livro de poesias. Para quem já trazia essa vivência e/ou intencionava produzir material didático, seria uma oportunidade para se familiarizar com as categorias e "testar" um protótipo do produto.

Para alcançar esses objetivos, na primeira aula comunicamos que a avaliação final consistia na entrega de um material didático, elaborado por equipes de até três integrantes. Durante o curso, essa posição foi revista em prol dos trabalhos: uma mestranda formada em artes ficou isenta de apresentar o produto para auxiliar na diagramação de três livros, e outra, com o mesmo perfil, integrou um dos grupos para elaborar um segundo material, o tapete pedagógico. Além das artistas plásticas, havia na turma uma estudante formada em letras (com experiência em trabalhos artísticos), duas pedagogas e dez licenciados em história. Dos 15, três eram recém-formados e não haviam tido experiência profissional em sala de aula (apenas os estágios realizados durante a graduação); cinco outros mestrandos lecionaram na educação básica por um ano mas não exerciam a docência naquele momento; quatro eram professores atuantes e outros três, além disso, exerciam cargos de coordenação ou direção.

Como consideramos importante exercitar uma linguagem acessível e não acadêmica, estabelecemos que o público-alvo deveria ser formado por estudantes da educação básica de qualquer nível, modalidade ou espaço educacional definido pela equipe. Quanto às temáticas, a única restrição é que contemplassem as linhas do programa. Como a pesquisa e a elaboração dos 
conteúdos eram de inteira responsabilidade das equipes, elas podiam escolher assuntos estudados nas outras disciplinas, que fossem objeto da própria pesquisa ou de conhecimento dos mestrandos. Não havia restrições de formato ou suporte, embora o aspecto visual fosse um item a ser avaliado. Qualquer que fosse a escolha, o material teria de vir acompanhado de um guia para o professor, contendo o referencial teórico e legal sobre o tema e/ou suporte, sugestões de atividades e projetos para trabalho em sala e, por fim, indicações de bibliografia de apoio, filmes e sites. Também solicitou-se um relatório no qual as equipes avaliassem o processo de elaboração. Os dois primeiros produtos levavam em conta a especificidade dos consumidores:

Diferentemente de outros livros de literatura em geral, a produção dos textos escolares tem um destinatário muito específico - o público escolar composto por professores e alunos. O público estudantil, a quem, em princípio se destinam os livros, é compulsório. Ou seja, não é ele quem escolhe a obra a ser lida ou a ser seu objeto de estudo, mas são obrigatoriamente usuários de determinados livros escolhidos pelos professores. Os livros escolares são utilizados de forma diferente das demais obras por terem o professor como intermediário constante que se encarrega de indicar inicialmente o livro a ser utilizado, as partes ou capítulos a serem objeto de estudo, assim como determina como o texto deve ser lido, e a partir da leitura são estabelecidas as atividades de escrita ou de oralidade a serem realizadas. A figura do professor é, portanto, fundamental no que se refere ao uso que se faz do livro, e seu poder reside, sobretudo, nesse aspecto de autonomia intelectual que tem permanecido com maior ou menor grau de liberdade no decorrer da história educacional. (Bittencourt, 2010, p.546-547)

Nas 16 semanas de curso, com quatro horas reservadas nas terças à tarde, foram adotados quatro tipos de atividades: aulas teóricas (4), conversa com convidados (4), tempo voltado para elaboração (4) e apresentação em sala da produção dos materiais (4). As aulas visavam subsidiar os estudantes ao abordar os conceitos, tipologias, funções, o processo de produção, distribuição e avaliação de materiais didáticos, sobretudo livros - formato escolhido pela maior parte das equipes. Vários desses temas, sobretudo a produção e avaliação, eram revistos na perspectiva dos convidados - três autores de materiais didáticos, um professor da educação básica e uma professora do ensino superior, não necessariamente de História. Pelo fato de trabalharem, os mestrandos 
preferiram que uma parte do curso fosse reservada à reunião das equipes para produção dos materiais. Esta foi acompanhada por orientações e apresentações nas fases de projeto, protótipo e entrega - feita em PDF para evitar grandes custos de impressão.

Ao final foram entregues sete materiais didáticos, acompanhados dos respectivos guias de orientação pedagógica (ver exemplos em anexo). Os três primeiros livros citados contaram com a diagramação de uma das mestrandas formadas em artes, e tiveram o mesmo layout, cujos elementos (cores, ícones, boxes etc.) variavam conforme o tema. Especificamente foram entregues:

- Dois livros ficcionais, voltados ao Ensino Fundamental II: A Caminho dos Quilombos (Livro do Aluno - LA - com 72p. e Livro do Professor - LP - com 38p., escrito por dois historiadores) e João de Deus do Nascimento: a grandeza de um mestre alfaiate (LA com 55p. e LP com 29p., escrito por um historiador e professor).

- Um livro de aprofundamento temático, voltado aos anos finais do Ensino Fundamental II e Ensino Médio: A Independência da Costa do Ouro (LA com 27p. e LP com 23p., escrito por um historiador).

- Um livro de aprofundamento temático, voltado para EJA (Ensino Médio): Pós-Abolição: Liberdade e Cidadania (LA com 22p. e LP com 10p., escrito por um historiador que também era professor e coordenador).

- Um livro digital, voltado a pré-vestibulares: O negro no Brasil: lutas e resistências (LA com 40p. e LP com 22p., escritos por dois historiadores, um dos quais atuava como professor).

- Um livro de contos adaptados, voltados ao Ensino Fundamental I, Reconto de Áfricas (LA com 39p. e LP com 89p.), acompanhado de um tapete pedagógico, elaborados por uma artista plástica, uma pedagoga e duas historiadoras que atuavam em escolas.

- Um calendário educativo sobre história local, para o Ensino Fundamental II: Calendário Popular de Cachoeira (14 folhas e LP com 21p., elaborado por uma historiadora, uma pedagoga e a mestranda formada em letras).

A avaliação consistiu em um parecer sobre cada produto, dado verbalmente e/ou por escrito após o fim do curso, e sobre os oito relatórios 
apresentados, sete das equipes autoras dos materiais e um da mestranda responsável pela diagramação.

\section{A ELABORAÇÃO DE MATERIAIS DIDÁTICOS PELOS MESTRANDOS}

A coleção didática e, em menor grau, o livro temático (paradidático) são os materiais de apoio ao ensino mais utilizados pelos docentes brasileiros, já que atualmente são distribuídos às escolas pelas ações governamentais do Programa Nacional do Livro Didático (PNLD) e do Programa Nacional da Biblioteca na Escola (PNBE). Talvez por conta disso, são os mais analisados nos cursos de licenciatura e nas pós-graduações, à luz da bibliografia temática ou específica do Ensino de História (Bittencourt, 2008, p.299ss). Assim, os saberes acadêmicos e curriculares operam a partir das leituras teóricas e dos guias governamentais, os quais auxiliam na construção de parâmetros de produção, ao passo que os saberes práticos obtidos com o contato prévio com os livros na sala de aula ajudam a estabelecer modelos. Por vivência profissional e/ou leituras, os mestrandos não desconheciam esse suporte, seus limites e imperfeições, o que gerou sensação de segurança no início do curso.

O peso da tradição escolar se fez presente na escolha do suporte livro pelas cinco equipes compostas exclusivamente por historiadores que escolheram produzir paradidáticos temáticos, mesmo quando procuraram incorporar recursos da cultura digital. $\mathrm{O}$ autor do Relatório 7 diz sobre suas escolhas a partir dos referenciais teóricos: "no meu caso, procuro acompanhar a Nova Historiografia da Escravidão, por isso, devo ressaltar mais os aspectos sociais, a agência dos sujeitos, as representações dos sujeitos sobre si e sobre o mundo" (2015, p.1). E aponta seus sentidos formativos:

o momento é oportuno para apresentar a escrita didática de temas importantes que vêm sendo estudados por historiadores brasileiros e de outras partes do mundo cuja experiência histórica foi marcada pela escravidão negra e, portanto, trazer para o chão da escola elementos capazes de contribuir para um novo paradigma das relações étnico-raciais. (Relatório 7, 2015, p.3) 
Do mesmo modo, o autor do Relatório 2 (2015, p.2) comenta:

O que nos intrigou para pesquisa, sendo a mola mestra para construção do paradidático, foi o fato desse sujeito histórico em questão possuir lugares de memórias em Salvador, tais como nome de ruas, estátua e letras de músicas, no entanto, sendo um desconhecido em sua terra natal. O livro paradidático, elaborado para alunos do $8^{\circ}$ ano do ensino fundamental (já que nesse ano se discute a temática da Revolta dos Alfaiates), tem a missão de relevar um pouco a História de João de Deus do Nascimento e levar esse sujeito a deixar de ser um desconhecido em Cachoeira, abrindo uma discussão sobre sujeitos históricos afrodescendentes, rejeitados ou ocultados há tempos em nossa Historiografia, passando, em tempos atuais, a serem reivindicados pelos movimentos negros, levando esses sujeitos históricos a ganharem novas abordagens e um melhor lugar na História do Brasil.

Esses trechos, e outros dos relatórios, apontam para o saber histórico acadêmico como referência para o conteúdo a ser trabalhado ou, como disse Allieu (1995, p.152 apud Monteiro, 2007, p.106), "as ciências históricas são a referência para não dizer o falso". Esta citação aponta para uma crítica da visão tradicional do saber escolar pautado na concepção de uma rígida "transposição didática", na qual a ciência determina o conteúdo do que vai ser ensinado na sala de aula, e ao professor cabe o papel de simplificador ou facilitador. No lugar, concebe-se a relação do docente com a ciência de maneira mais "ascendente", pois lhe cabe ativamente a mobilização de tais saberes acadêmicos, de maneira nem sempre rígida, conjugado com outros saberes e finalidades provenientes da cultura escolar e do contexto de ensino. Allieu prefere denominar esse processo de interpelação porque, segundo Monteiro, "para atribuir sentido ao que ensina, o professor recorre ao saber acadêmico, em suas diferentes escolas e matizes teóricos, para buscar subsídios que lhe permitam produzir versões coerentes com seus pontos de vista e que tenham uma base de legitimidade dentro do campo" (ibidem).

Observamos algo parecido, com algumas peculiaridades no caso da disciplina de mestrado profissional. Os historiadores/licenciandos estavam envolvidos em pesquisas acadêmicas em História, precisando lidar com suas etapas como a pesquisa de fontes e diálogos com a bibliografia temática e teórica. Realizam, portanto, um diálogo com dois saberes que estão sendo paralelamente construídos - o acadêmico, a ser defendido no final de 2 anos 
(como dissertação ou outros formatos), e o didático, a ser apresentado na disciplina. Portanto, o primeiro motivo pelo qual fica difícil falar em "transposição" é que não há um saber acadêmico pronto para ser trabalhado pelo mestrando no paradidático, mas um diálogo historiográfico em curso, indefinido e ainda em aberto. O segundo motivo é que o eixo central da escolha é político, almejando-se intervenção contra o racismo e desigualdade racial. Tais escolhas políticas justificam a eleição do tema de pesquisa e do material didático. Nota-se, porém, como no primeiro trecho a intervenção política integra a posição teórico-historiográfica, ao passo que no segundo se concebe como oposta a ela, criticada nos seus silêncios, e coloca sua origem nas demandas dos movimentos sociais negros.

Além disso, na escolha levam-se em conta os aspectos da experiência, relacionados ao conhecimento do público-alvo. Isso foi determinante principalmente na escolha do tipo de paradidático a ser produzido. Em três dos cinco materiais de historiadores escolheu-se produzir textos informativos, nos quais a narrativa dos processos vinha acompanhada de imagens, em dois deles funcionando como ilustração. Nesses casos pouco se justificou a opção; quando muito se apontavam, bem rapidamente, outros sentidos formativos além de passar a informação, como "acreditamos estar de algum modo a contribuir com a habilidade de ler textos verbais" (Relatório 7, 2015, p.2). A justificativa é mais extensa nos dois paradidáticos ficcionais:

a princípio faríamos um livro contando a história de João de Deus, baseando-se no que já foi escrito, sem construção de enredo. Só focando no objeto de estudo. Porém procurei usar a criatividade, na busca de atingir uma linguagem acessível ao público alvo, composto de adolescentes, criando um enredo que atraísse o aluno leitor, fazendo um texto onde a temática fosse aparecendo levemente, onde sem perceber, pudesse aprender a História de nosso personagem. Por isso me aventurei na criação de um enredo que teve como fio condutor uma família cachoeirana que fora passar férias em Salvador e lá teve acesso ao monumento (na Praça da Piedade) e à rua João de Deus (no Pelourinho), fazendo um link com a adolescente que passara para o $8^{\circ}$ ano e teve a felicidade de conhecer mais sobre a Revolta dos Alfaiates, onde a estudante e seu grupo vão falar do episódio, dando um destaque final para o cachoeirano João de Deus do Nascimento. (Relatório 2, 2015, p.2) 
Tanto no autor desse material quanto nos autores de "A Caminho do Quilombo" a estratégia parte da projeção sobre o público-alvo, que justifica não apenas a opção pela narrativa de ficção como as estratégias de elaboração do enredo. O conteúdo sobre o passado a ser ensinado (o saber historiográfico) é integrado aos elementos dos contextos locais dos jovens leitores, que o autor conhece a partir da própria experiência tanto do espaço escolar quanto do cotidiano das comunidades e/ou cidades mencionadas. São os saberes da experiência, integrados aos saberes pedagógicos (ligados ao "como ensinar"), que determinam a escolha da estratégia de apresentação. Isso é mais forte no caso da equipe que elaborou o "Calendário Popular de Cachoeira". Como não foi pensado com base em pesquisas acadêmicas, o conteúdo foi selecionado a partir da observação do cotidiano de Cachoeira: "O mesmo calendário foi pensado a partir da observação de uma análise das narrativas da população, onde constatou-se que algumas personalidades, lugares, instituições, festejos e acontecimentos vivenciados na cidade possuem um significado relativo na vida dessas pessoas" (Relatório 8, 2015, p.1). Portanto, tem-se uma produção didática que parte de saberes geograficamente localizados, tanto no nível do conteúdo quanto no do público-alvo, e que integra saberes acadêmicos para finalidades políticas e pedagógicas.

Toda essa experiência e sentidos atribuídos passaram por um estranhamento quando, na disciplina "Metodologia da Pesquisa e da Produção de Materiais Didáticos", os mestrandos tiveram seu papel de consumidor, professor, analista e/ou pesquisador deslocado para o de produtor. Na fala de um professor historiador, um importante aprendizado ocorreu quando passou "a ter uma certa noção do trabalhão que é montar um material como esse" (Relatório 2, 2015, p.5). Os efeitos do deslocamento foram traduzidos em imagem por uma dupla de professores de História: "Parecíamos que nós nunca iríamos concluir, e, às vezes, achávamos que estávamos em um grande labirinto, sem encontrar uma saída. O medo do desconhecido era o que nos acompanhava e ao mesmo tempo era o que nos desafiava" (Relatório 5, 2015, p.4). O tom angustiado e a sensação de estar perdido são generalizados e perduraram até a entrega dos trabalhos. Por isso permeiam os relatórios, a exemplo de uma mestranda que avalia "o processo de construção deste livro como algo árduo, doloroso, sofrido, semelhante apenas ao processo de escrita do Trabalho de Conclusão de Curso vivenciado por mim há cerca de 2 anos. Já não me 
lembrava de como foi dormir e acordar pensando nisso" (Relatório 3, 2015, p.8). A maneira imprevisível e não-linear com que são produzidos foi reconhecida nos relatos, é expressa por um licenciado em História mediante uma analogia com a narrativa acadêmica: "como na História, o processo de composição desse trabalho não se deu de forma linear, e assim, refletimos, construímos e desconstruímos o tempo todo, exercício inerente e necessário a uma tarefa com tais peculiaridades" (Relatório 3, 2015, p.10).

A angústia dos estudantes teve razões concretas, apontadas nos relatórios como dificuldades do processo:

1. Diagramação/edição.

2. Adequação dos conteúdos e linguagem ao público-alvo.

3. Atividades para o professor, exercício do pensar pedagógico.

4. Tempo reduzido devido a muitas tarefas, seja do trabalho seja de outras disciplinas do Mestrado.

5. Lidar com diferenças e visões conflitantes no trabalho em equipe.

Os três últimos itens apareceram de maneira ocasional nos relatórios. Sem causar muito alarde, dependiam das limitações e condições de quem elaborava o material, como a familiarização com a prática docente, o maior ou menor tempo disponível (em função de bolsa, licença remunerada, disciplinas já cursadas etc.) e a organização na produção (sozinho ou em equipe, com ou sem suporte externo). Foram vistos como acidentes de percurso e foram referenciados de maneira breve.

Esse não é o caso dos itens considerados mais difíceis, como a editoração/ diagramação, unanimemente apontado pelos mestrandos, como o historiador professor do Relatório 7: “a principal dificuldade enfrentada na elaboração desse protótipo de livro paradidático foi de natureza técnica. Seria preciso um contato maior com profissionais das artes visuais, da comunicação visual, editores etc." (Relatório 7, 2015, p.2). A mesma dificuldade foi apontada pelo historiador do Relatório 1 (2015, p.6): "a ausência de meios para a realização do material como pedagogo, um ilustrador, diagramador, editor, isto é, de profissionais que poderiam acrescentar de maneira efetiva na construção de um material complementar que pudesse atender as demandas dos estudantes, dos professores e se preciso fosse da sociedade". 
Na mesma página, ele pontua que

afinal de contas é praticamente impossível a realização de um material didático apenas por um profissional. Apesar de o mesmo ter experiência em sala de aula, trabalhar com livros didáticos, analisá-los em muitas ocasiões durante o processo de ensino aprendizagem, a construção de um material deste porte não pode ser jamais feita por um historiador, geógrafo, biólogo, matemático, enfim é necessária uma gama de profissionais que possam subsidiar a criação de um material que possa suplantar as necessidades de educandos e educadores. (Relatório 1, 2015, p.6)

No trecho citado do Relatório 1 esse aprendizado aparece como vindo da própria atividade de elaboração, primeiramente como dificuldade e depois como uma conclusão mais geral. Explicita como os saberes acadêmicos e pedagógicos, apesar de importantes, não são suficientes, ou, em outras palavras, não basta ser professor e/ou pesquisador para produzir materiais (livros) didáticos, já que a pesquisa, a escrita e a didatização são permeadas pela confecção. Esta se desdobra na materialidade e na visualidade do suporte e, juntas, integram o consumo do público, também mencionado no trecho. A novidade que tornou a empreitada desafiadora aos olhos dos mestrandos foi que a consecução do objetivo de produzir um livro didático, mesmo que realizado por uma única pessoa, exigia mobilização prática de referências e saberes de diversos níveis de complexidade e interdisciplinaridade - historiográficas, pedagógicas, estéticas e linguísticas - apontados pela recente bibliografia sobre o tema (Bittencourt, 2008; Munakata, 1997).

Tal percepção foi construída nos meses de trabalho ao longo da disciplina de mestrado, na qual o diálogo multidisciplinar - amador, no nosso caso - foi próximo do que Munakata (1997) descreve na sua tese: os saberes de diferentes áreas se interligavam em etapas diferentes da produção, com o autor historiador conduzindo o processo de redação e dialogando com o responsável pela diagramação e pela arte. Em três produtos esse trabalho foi feito por uma profissional de artes responsável pela tarefa dentro da disciplina. Por opção dos autores de outros dois livros paradidáticos de história, a diagramação foi feita por um integrante da própria equipe e, no último, por um profissional externo ao mestrado. Em dois materiais não livros (calendário e livro de contos com tapete pedagógico), com equipes integradas também por pedagogos e 
artistas, o processo criativo foi interdisciplinar desde o princípio. Mesmo para as equipes que tiveram suporte de membros com formação em artes, pensar o aspecto da visualidade do material ou livro foi uma experiência inédita, pois implicava adequar a percepção estética a um fim pedagógico considerando as especificidades do saber histórico escolar. A ajuda de artistas diagramadores não impediu que membros de três equipes pensassem e atuassem nessa dimensão:

Me aventurei em colocar algumas fotos sobre Cachoeira no livro do aluno e aprendi muito com esse processo, criei os boxes, com os ícones em forma de balão ([a diagramadora] coloriu), criei alguns nomes dos boxes e outros nomes sugeridos pelos colegas que aproveitei; além disso, o guia do professor foi feito com a diagramação do livro do aluno, pois aproveitei o modelo e fui transferindo os ícones e cores, exercitando o lado de diagramador (bem amador!). Apesar da dificuldade, gostei do resultado final. (Relatório 2, 2015, p.5)

Diferentemente da diagramação, supúnhamos que licenciados e professores tivessem familiaridade com a comunicação destinada aos alunos da educação básica. Porém, não foi o que aconteceu, já que outra dificuldade enfrentada pela maior parte dos mestrandos historiadores foi a escrita para um público não acadêmico:

Escrever também para uma diversidade etária foi do mesmo modo uma maneira de aprendizado, a graduação dos cursos de licenciatura e bacharelado em História não prepara a escrita para estudantes de ensino fundamental II e nem para o ensino médio, esta capacidade vai se desenvolvendo em experiências como as ofertadas nesta atividade. (Relatório 1, 2015, p.7)

percebemos que o material didático e paradidático exige um nível de escrita criativa, linguagem que se diferencia e por vezes se afasta um pouco do texto acadêmico. O conhecimento é abordado num jogo de articulação com uma escrita que dialoga com um público específico de leitores(as) da faixa etária a que se destina o material. No entanto, para além disso, não se trata simplesmente de adequar a linguagem conforme a série/ciclo escolar dos(as) estudantes, mas antes, e, sobretudo, trata-se de elaborar um texto que seja capaz de abordar uma temática histórica numa perspectiva por vezes literária. Dinâmica que envolve conhecimento e criatividade num movimento em torno da ludicidade. (Relatório 3, 2015, p.10) 
Por produzir um paradidático ficcional, o segundo trecho comenta o processo de escrita de uma maneira mais complexa porque teve de deparar com os problemas da narrativa, menos evidentes mas não ausentes num material que se propõe informativo. Suas percepções podem ser generalizadas: a especificidade do público-alvo demanda um texto inteligível do ponto de vista sintático e semântico, e envolvente do ponto de vista narrativo, pois o aprendizado significativo por meio do livro pressupõe que o estudante o entenda e se interesse. Como aponta Circe Bittencourt ao falar da história escrita para a escola:

Há uma tendência em estabelecer qualidade de livro ao nível acadêmico dos autores, criando-se uma relação entre capacidade científica acadêmica e capacidade de elaborar um manual ou textos didáticos para o ensino fundamental e médio. Esta concepção de que os "sábios" seriam os intelectuais mais aptos para a confecção de obras escolares foi comum entre vários administradores encarregados das políticas públicas das primeiras décadas do século XIX. Essa ideia ainda permanece disseminada e sugerida em algumas análises feitas em relação aos livros didáticos que sustentam a necessidade da fidelidade do ensino de determinado conhecimento escolar ao que é produzido pela academia ... Entretanto, a produção de textos didáticos exige mais do que o domínio e atualização do conhecimento científico e acadêmico. Escrever textos para alunos de faixas etárias diversas das do autor, que possui uma vasta cultura letrada e que precisa estabelecer uma comunicação de aprendizado com quem ainda se encontra em fase inicial de domínio das letras e em fase de formação intelectual, exige um conhecimento sobre práticas em sala de aula e de algum tipo de contato com o cotidiano escolar. Escrever obras didáticas exige experiências mais complexas e, muitas vezes, as obras mais bem sucedidas são fruto de equipes de autores que, juntamente com editores e técnicos gráficos, elaboram os textos e os transformam em material didático. (Bittencourt, 2010, p.549-550)

Tal estilo de escrita difere daquele praticado na academia e também da oralidade da sala de aula, estando mais próxima de uma escrita jornalística destinada a um amplo público, com características próprias da literatura infanto-juvenil quando se vale de uma narrativa. Como qualquer outra habilidade, depende menos de um saber formalizado ou de regras que de uma prática orientada, exercitada e disciplinada. O desabafo do primeiro mestrando pode ser generalizado, já que esse tipo de escrita é pouco ou nada trabalhado nos cursos de licenciatura em História, motivo pelo qual os profissionais 
formados nessa área relatam dificuldades que tiveram em desenvolvê-la, mesmo quando dominavam o tema e escreviam para alunos de idade mais avançada. Assim como a diagramação, o aspecto da produção textual precisa ser levado em conta e, se for o caso, trabalhado junto aos professores em formação nos programas de mestrado profissional.

Depois de elaborados, os livros tiveram distintos empregos. A biografia sobre João de Deus, que seria o protótipo do Trabalho Final de curso, não teve o uso esperado porque seu autor optou por defender uma dissertação. O módulo para EJA foi utilizado na escola onde o mestrando era docente e diretor. Os livros sobre educação quilombola foram apresentados no III Encontro Estadual de Ensino de História e, durante tirocínio, em um módulo da Pós-Graduação lato sensu em História da África, voltado à formação continuada de docentes da região do Recôncavo. O livro de recontos para Ensino Fundamental I foi inscrito em um edital estadual voltado ao fomento de ideias inovadoras promovido pela Fundação de Amparo à pesquisa da Bahia (Fapesb). Além disso, se houver recursos financeiros, os mestrandos pretendem publicar todos os materiais em suporte impresso e/ou digital no site do Laboratório de Ensino de História do Recôncavo da Bahia (LEHRB). Toda essa movimentação aponta para os desdobramentos acadêmicos e educacionais dessa produção após a disciplina "Metodologia da Pesquisa e da Produção de Materiais Didáticos", cumprindo os objetivos dos Mestrados Profissionais em História de gerar conhecimento relevante e passível de intervenção social pelos próprios profissionais, os educadores.

\section{Produção de Materiais Didáticos no Mestrado Profissional em História}

Com a recente expansão dos Mestrados Profissionais em História, vários dos quais com área de concentração e linhas de pesquisas focadas no Ensino, também se tornaram espaços de produção e uso de materiais didáticos ao permitirem trabalhos finais de curso além da tradicional dissertação. A experiência na disciplina "Metodologia da Pesquisa e da Produção de Materiais Didáticos" permitiu simular esse trabalho. Os mestrandos precisaram atender os requisitos legais (como a Lei 11.645) e lidar com as dimensões historiográfica e pedagógica e, ainda, com a linguagem ou suporte - isto é, precisaram 
trabalhar a dimensão textual e gráfico-editorial para livros e folhetos -, além de elaborar um guia para o professor.

Como os alunos do mestrado não estavam presos à busca por lucro, houve diversidade nos temas tratados e experimentação nas formas de apresentação. No processo de elaboração, saberes de diversas naturezas foram mobilizados, destacando-se o papel das finalidades político-sociais, o conhecimento das realidades locais e do público-alvo como eixos fundamentais das escolhas, a partir dos quais se integravam saberes acadêmicos e pedagógicos. Vimos que a dificuldade maior da produção repousou no trabalho com a dimensão da linguagem para o público-alvo e a do suporte dos materiais, as quais envolvem saberes práticos que estão mais distantes da formação e atuação dos mestrandos. Isso ocorreu apesar do perfil interdisciplinar dessa turma, uma contingência que pode não ocorrer nos anos seguintes. Como as narrativas dos mestrandos apontaram, longe de ser um "mal necessário", a experiência interdisciplinar se constituiu como fator formativo que, no mínimo, modificou o olhar sobre os materiais didáticos a partir do conhecimento prático de sua confecção.

A experiência permitiu adiantar uma questão importante para as próximas etapas: como lidar, em um mestrado disciplinar em História, com a multiplicidade de áreas e saberes inerente à produção de materiais (didáticos) no Trabalho Final de Curso? Dentre os encaminhamentos possíveis, há a possibilidade de apresentar apenas o conteúdo ou protótipo, para posterior tratamento técnico; exigir que o mestrando traga esse conhecimento ou que o busque por conta própria; e fornecer suporte permanente na instituição para o tratamento técnico e divulgação do material. Esta opção seria ideal por liberar os estudantes de tais preocupações, permitir um diálogo interdisciplinar formativo e criar perspectivas de, ao final do processo, ter produtos acabados disponíveis para a comunidade da região. Porém, atualmente, ao menos na UFRB, ela esbarra nos desafios de financiamento, presentes desde a criação dessa modalidade de mestrado, mais dramáticos na área de humanas. Outras soluções possíveis, algumas já adotadas em outros programas de pós-graduação, são compor o quadro com docentes capazes de orientar e lidar com a dimensão técnica, suprir a lacuna através de co-orientações externas, ou buscar financiamentos pontuais como editais e projetos. Tais possibilidades não se excluem e podem ser combinadas a partir da situação de cada Programa em 
determinado momento, da bagagem do orientador e mesmo de cada mestrando.

De qualquer forma, tais iniciativas dos Mestrados Profissionais em História brasileiros procuram responder aos desafios de realizar a formação continuada e crítica na pós-graduação mediante e em paralelo com a pesquisa aplicada em História. Ambas podem fundamentar uma guinada relevante no campo da produção didática no país ao subsidiar acadêmica e tecnicamente a elaboração sistemática e contínua de materiais pelos próprios professores. É uma maneira de fazer emergir conteúdos e saberes locais/regionais, compartilhados com a escola e com a comunidade na qual o professor se insere e/ou atua, frequentemente em diálogo com a historiografia produzida nas Instituições de Ensino Superior dessas regiões, sobretudo nas periferias do país. Uma jornada coletiva de aprimoramento técnico e temático, reflexivo e crítico, de forte acento interdisciplinar, que apenas se inicia.

\section{REFERÊNCIAS}

AFONSO, Cláudia Regina Amaral. O Mestrado Profissional em Ensino de História, entre a práxis e o pragmatismo: o papel indutivo da CAPES. Resumo no Simpósio Temático 068 do SIMPÓSIO NACIONAL DE HISTÓRIA - ANPUH, XXVIII, 2015. Disponível em: http://www.snh2015.anpuh.org/; Acesso em: 15 jul. 2015.

ANPUH. Fórum de PPGH. Disponível em: http://site.anpuh.org/index.php/documentos/forum-de-ppgh; Acesso em: 15 jul. 2015.

. Mestrados Profissionais: Posição da Diretoria Nacional da ANPUH-Brasil. 15 jun. 2012. Disponível em: http://www.anpuh.org/informativo/view?ID_INFORMATIVO=3165; Acesso em: 15 jul. 2015.

. Simpósio Nacional de História - Lugares dos Historiadores: Velhos e Novos Desafios, XXVIII, 2015, Florianópolis, SC. Anais eletrônicos..., 2015. Disponível em: http://www.snh2015.anpuh.org/site/anaiscomplementares; Acesso em: 15 jul. 2015.

BITTENCOURT, Circe. Ensino de História: fundamentos e métodos. 2.ed. São Paulo: Cortez, 2008.

. Livros didáticos de história: práticas e formação docente. In: SANTOS, Lucíola L. C. P. et al. (Org.) Convergências e tensões no campo da formação e do trabalho docente. Belo Horizonte: Autêntica, 2010. p.544-563. Disponível em: http:// endipe.pro.br/site/eventos-anteriores/; Acesso em: 6 abr. 2013.

CAPES. Documento de área e Comissão da Trienal, 2013. Disponível em: http://www. 
capes.gov.br/component/content/article/44-avaliacao/4639-historia; Acesso em: 15 jul. 2015.

CAPES. Portaria Normativa n. 17 - dispõe sobre o Mestrado Profissional no âmbito da Fundação Coordenação de Aperfeiçoamento de Pessoal de Nível Superior CAPES, de 28 dez. 2009. Disponível em: http://www.foprof.org.br/documentos/ portaria-normativa-mec-n17-28-12-2009.pdf; Acesso em: 15 jul. 2015.

. Sistema Nacional de Pós-Graduação (SNPG). Cursos Recomendados e Reconhecidos (por área). Disponível em: http://www.capes.gov.br/cursos-recomendados; Acesso em: 15 jul. 2015.

FERNANDES, Débora Araújo; BRINGEL, Eliane Leite Barbosa; LIMA, Jorge Ferreira. A História e seu ensino na concepção dos professores/mestrandos em História. Revista Labirinto. Porto-Velho, RO, ano XV, v.22, p.105-117, 2015. Disponível em: http://www.periodicos.unir.br/index.php/LABIRINTO/article/viewFile/1290/1419.

FISCHER, Tânia. Proposições sobre Educação Profissional em nível de Pós-Graduação para o PNPG 2011-2020. In: BRASIL, Ministério da Educação. Coordenação de Aperfeiçoamento de Pessoal de Nível Superior. Plano nacional de Pós-Graduação - PNPG 2011/2020/Coordenação de Pessoal de Nível Superior - Brasília, DF: CAPES, 2010. 2v. Disponível em: http://www.foprof.org.br/download/pnpg-2011-2020-educacao-profissional.pdf; Acesso em: 15 jul. 2015.

GRINBERG, Keila. Pós-graduação ao rés-do-chão. Coluna Em Tempo. Ciência Hoje, 5 dez. 2014. Disponível em: http://cienciahoje.uol.com.br/colunas/em-tempo/ pos-graduacao-ao-res-do-chao.

MATOS, Júlia; SENNA, Adriana Kivanski de. Mestrado profissional de história e a formação docente para a pesquisa. Revista Latino-Americana de História, v.2, n.6, ago. 2013 - Edição Especial PPGH Unisinos. Disponível em: http://projeto.unisinos.br/rla/index.php/rla/article/view/190/144; Acesso em: 5 fev. 2016.

MONTEIRO, Ana Maria. Professores de História: entre saberes e práticas. Rio de Janeiro: Mauad X, 2007.

MUNAKATA, Kazumi. Produzindo livros didáticos e paradidáticos. Tese (Doutorado em História e Filosofia da Educação) - Programa de Estudos Pós-Graduados em Educação: História, Política, Sociedade, Pontifícia Universidade Católica de São Paulo. São Paulo, 1997.

QUELHAS, Osvaldo Luiz Gonçalves; FARIA FILHO, José Rodrigues; FRANÇA, Sergio Luiz Braga. O mestrado profissional no contexto do sistema de pós-graduação brasileiro. Revista Brasileira de Pós-Graduação, v.2, n.4, p.97-104, 2005. Disponível em: http://ojs.rbpg.capes.gov.br/index.php/rbpg/article/view/82/78; Acesso em: 15 jul. 2015.

RADÜNZ, Roberto. Mestrado Profissional em História: o desafio do trabalho de Conclusão de Curso. Opsis, Catalão, GO, v.15, n.1, p.149-163, 2015. Disponível em: 
https://www.revistas.ufg.br/index.php?journal=Opsis\&page=article\&op=view\&p ath\%5B\%5D=34728\&path\%5B\%5D=20041; Acesso em: 15 fev. 2016.

TARDIF, Maurice. Saberes docentes e formação profissional. Petrópolis, RJ: Vozes, 2002.

UFG/Catalão. Programação. II Simpósio Nacional de História - UFG/Catalão, II Encontro Nacional dos Mestrados Profissionais em História, XII Simpósio de História de Catalão. 2015. Disponível em: http://inhcs-eventos2015-com.webnode.com/ cronograma/; Acesso em: 14 fev. 2016.

UNIFAL. Programação. I Congresso Internacional - Península Ibérica: Antiguidade, Medievo e suas projeções para o século XVI \& I Encontro Nacional dos Mestrados Profissionais da área de História. 2014. Disponível em: http://www.unifal-mg.edu. br/extensao/?q=1814_i_congress_intern_peninsula_iberica_progr; Acesso em: 14 fev. 2016.

UFRB. Mestrado Profissional em História da África, da Diáspora e dos Povos Indígenas. 2014. Disponível em: http://wwwl.ufrb.edu.br/mphistoria/; Acesso em: 15 jul. 2015. 


\section{ANEXOS - PÁGINAS DOS LIVROS PARADIDÁTICOS PRODUZIDOS}

Figura 1 - Capa e folha de rosto do livro do educador A caminho dos Quilombos

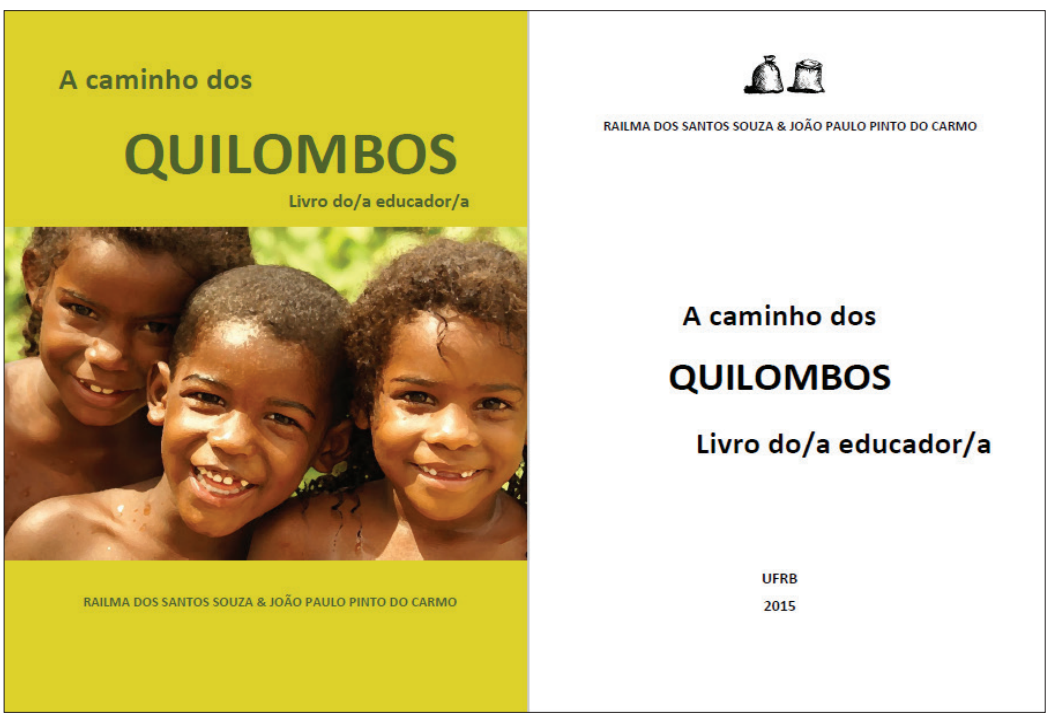

Figura 2 - Páginas do livro do aluno A caminho dos Quilombos

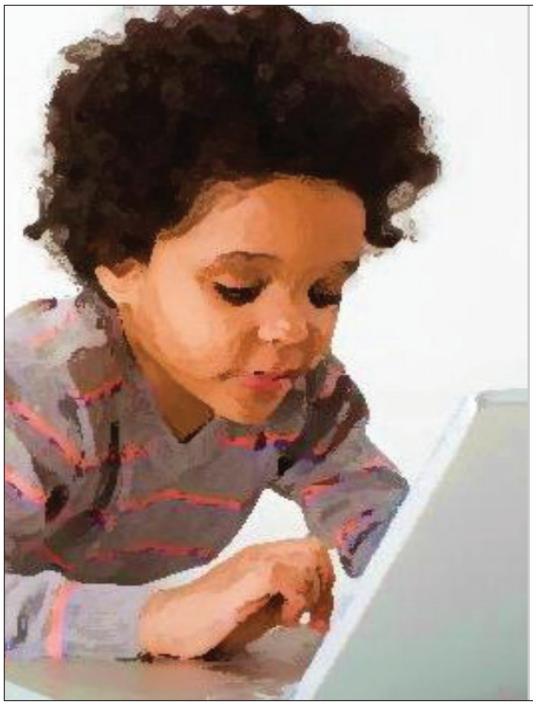

\section{DI \\ DESCOBRINDO O QUILOMBO}

Primavera, dia quente e ensolarado em uma cidade do Recôncavo baiano chamada Cachoeira! Fred acorda super disposto e num pulo, antes mesmo de escovar os dentes, senta-se em frente ao computador. Ao acessar uma rede social vê a atualização de status da sua professora de História, Karine, sobre o reconhecimento de algumas comunidades quilombolas na Bahia pela Fundação Cultura Palmares. Fred, surpreso com a notícia, grita:

\section{-Mãeeeeeeeeeeeeeeeeee!!!!!}

A sua mãe, Núbia, assusta-se com o grito do filho e vem correndo ver oque está acontecendo?

- Foi o que filho?

A Fundação Cultural Palmares é uma entidade de preservoçâ e valorização da arte e culturo

Fred: - Mãel Olha só o que a professora de História postou aqui!!!! Ela está dizendo que a Fundação Palmares reconheceu algumas comunidades enquanto quilombolas, fro-brasileiras, vinculada an Ministério da Cultura. É responsável pela titulação reconhecimento das comunidades quilombolas 
Figura 3 - Capa, primeiro mês e caderno do professor do Calendário Popular de Cachoeira

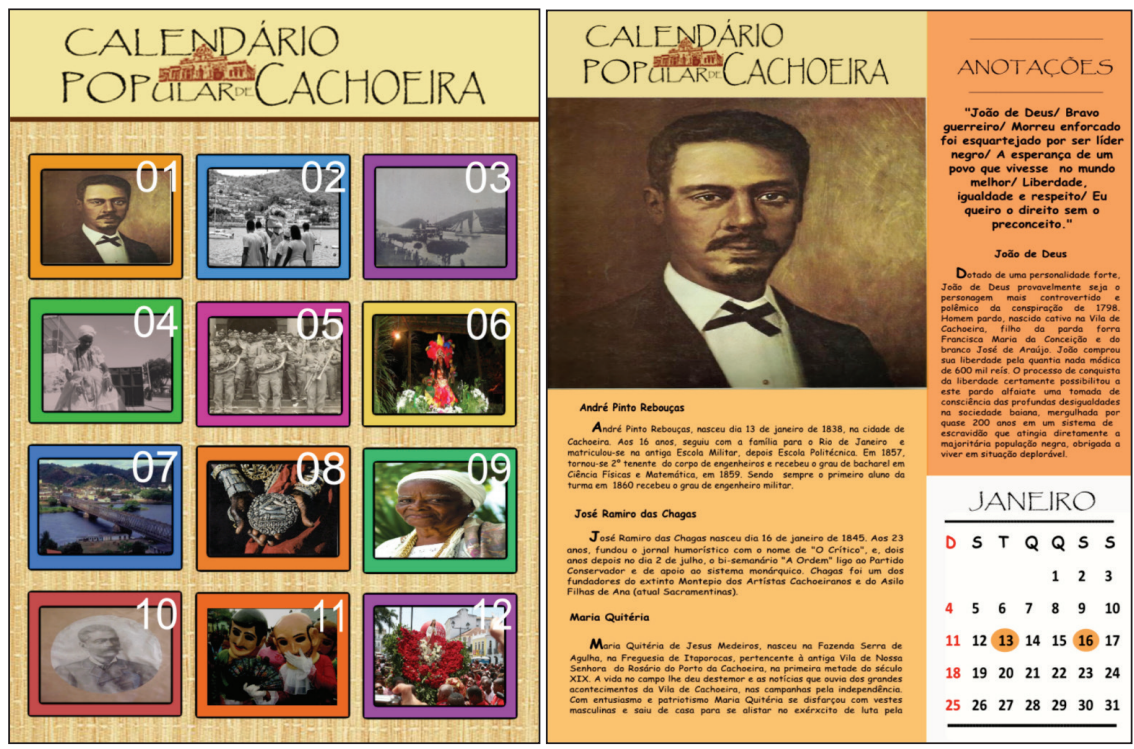

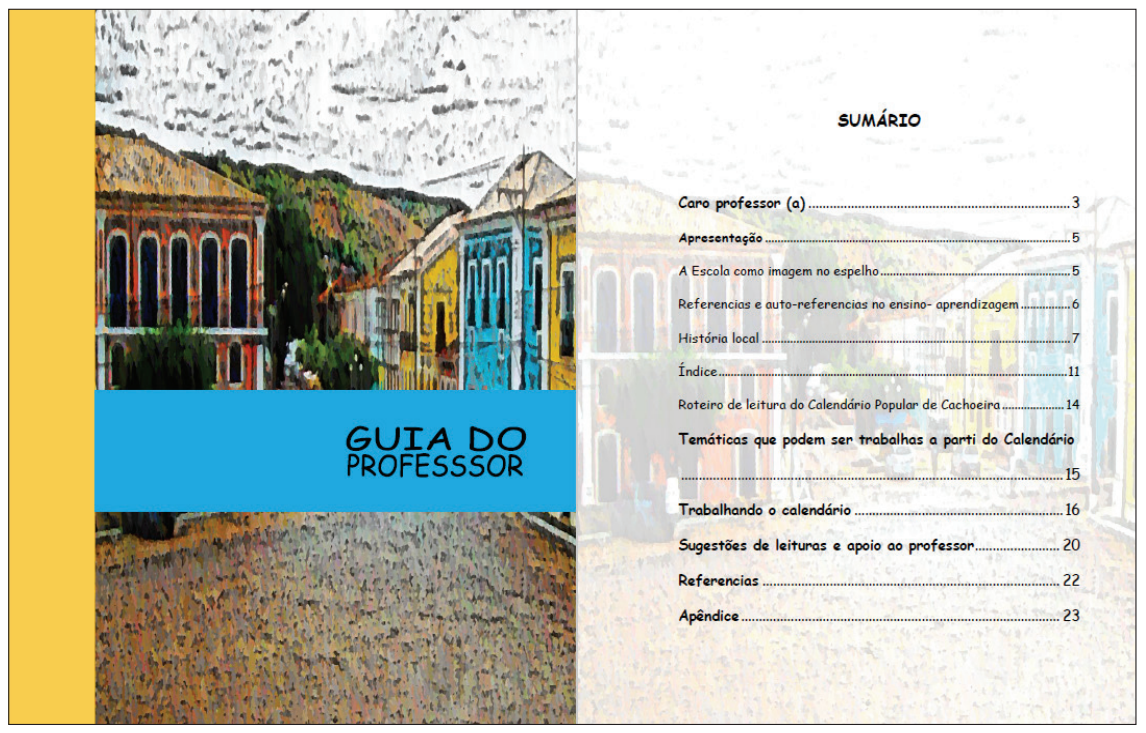


Figura 4 - Folha de rosto e primeira imagem do livro do aluno (Re)contos de Áfricas

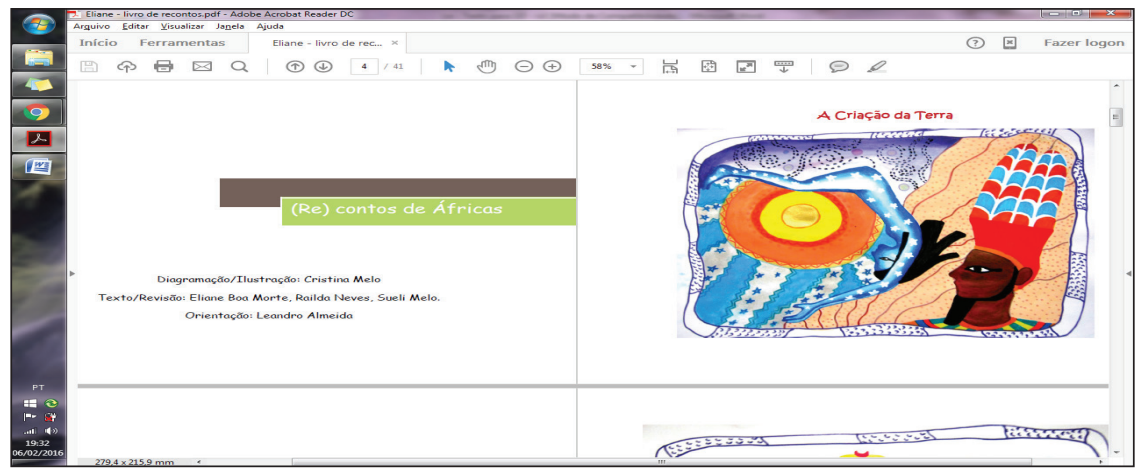

Figura 5 - Sumário e apresentação do livro da professora do material (Re)contos de Áfricas

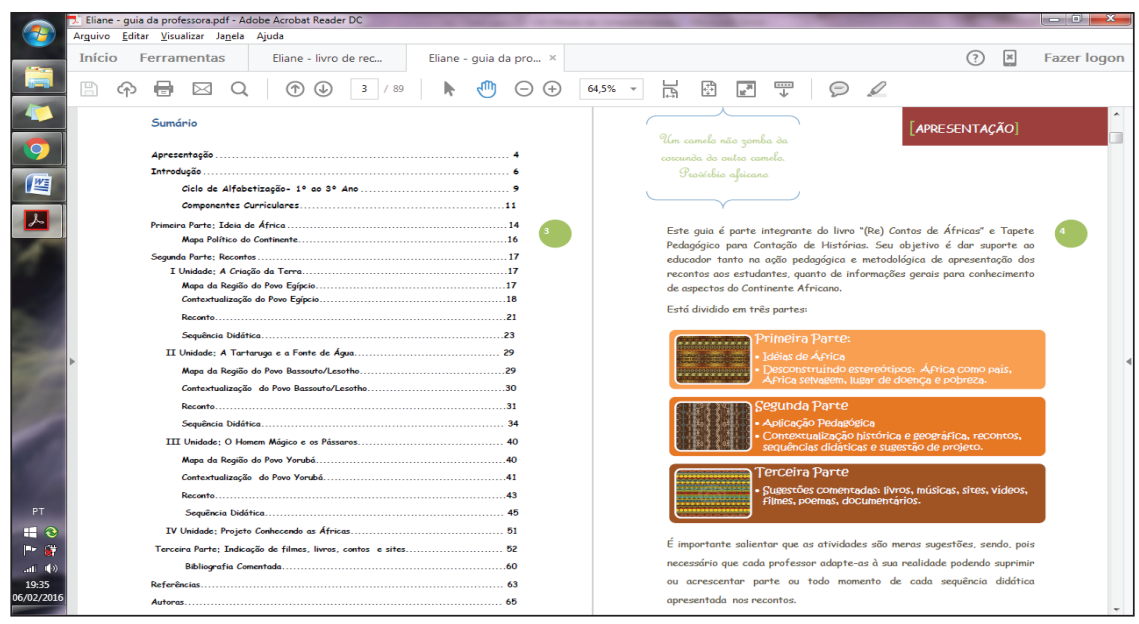


Figura 6 - Fotos de um dos tapetes pedagógicos que acompanham o livro do aluno (Re)contos de Áfricas

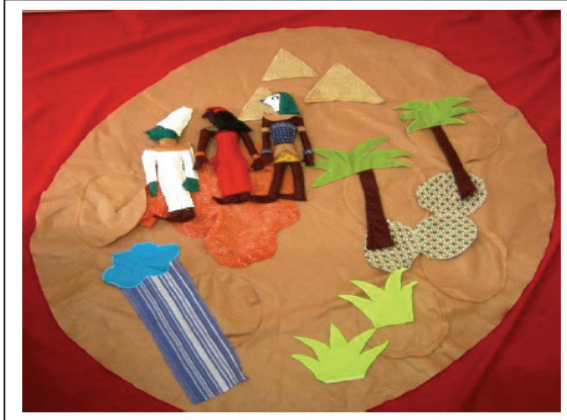

A família no Egito

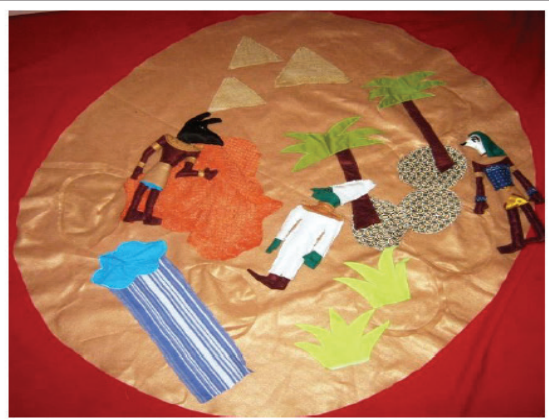

Seth briga com Osíris por inveja

Figura 7 - Páginas do livro do aluno "O Negro no Brasil: Lutas e Resistências". Em azul, links que remetem a verbetes da Wikipedia

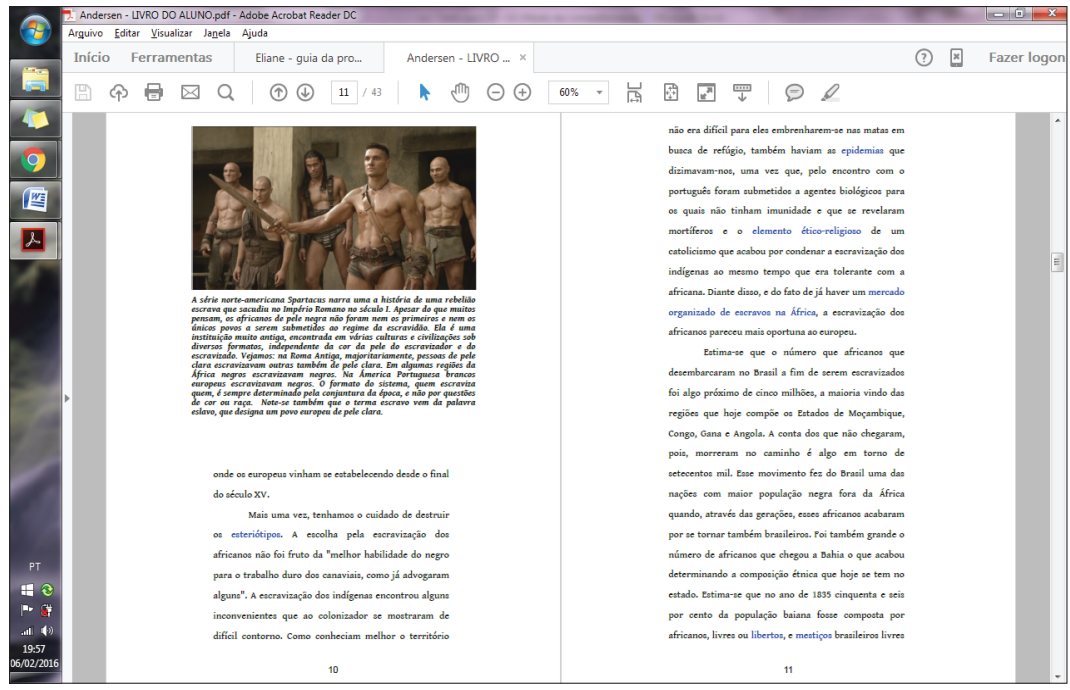


Figura 8 - Páginas do livro do aluno Pós-Abolição: Liberdade e Cidadania Educação de Jovens e Adultos (Tempo Formativo III)

\begin{tabular}{|c|c|}
\hline 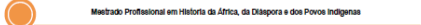 & UNVERSIDADE FEDERAL DO RECONCAVO DABAAHA \\
\hline & Comeinoraçêes do 13 de Maio de 1888 \\
\hline \multicolumn{2}{|l|}{ precisa ser denunciada e enfientada pelos poderes püblicos, entidades da sociedade civil organi- } \\
\hline \multicolumn{2}{|l|}{$\begin{array}{l}\text { zada e, principalmente, pelos trabalhadores e trabalhadoras subneidos a esse tipo de explora- } \\
\text { ção. }\end{array}$} \\
\hline \multicolumn{2}{|l|}{ Ao longo da histónia do nosso pais, a escravizaçáo de populaạóes indigenas e de poros do } \\
\hline \multicolumn{2}{|l|}{ continente aficicno foi intensa e garantida pelo ordenamento juridico, durante a Colônia eo Im- } \\
\hline $\begin{array}{lll}\text { pério; ou seja, diferente de hoje, a escravidão não era crime! } & \begin{array}{l}\text { A provincin da Bahia, zo } \\
\text { ano de } 1887 \text {, possuia ceraca }\end{array}\end{array}$ & 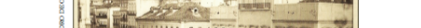 \\
\hline Apenas para lembramos, o Brasil foi o último pais da América a de 76.838 escraves A Aa- & 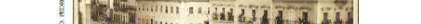 \\
\hline Latina a abolir formalmente o tabalho escravo. Longe de ser um ato his en a quarta provincia & 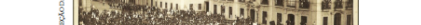 \\
\hline 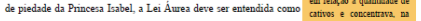 & \\
\hline - desdobramento das lutas entiescravocratas inclusive aquelas tava- época da aboliçố. 10\% da & \\
\hline 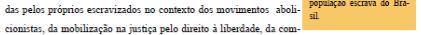 & 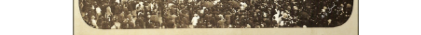 \\
\hline $\begin{array}{l}\text { cionistas, da mobiliząăo na justiça pelo direito à liberdade, da com- } \\
\text { pra de alforma eda fugaga. }\end{array}$ & \multirow{2}{*}{ 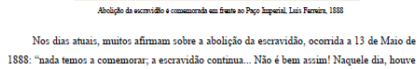 } \\
\hline $\begin{array}{l}\text { Na segunda metade do século XIX, o abolicionismo contava com nuitos simpatizantes e } \\
\text { militantes e a ão é exagero dizer que mobilizou setores populares e médios da populaçâo em ge- }\end{array}$ & \\
\hline $\begin{array}{l}\text { dada para compreender os seus limites e consequiências para o presente, quando ainda lutamos } \\
\text { contra a exchusâo social, econômicz e cultural dz populaç̧o negra. }\end{array}$ & $\begin{array}{l}\text { cóncavo Baiano, os festejos foram animados pela Flananônica Lyra Cecilana, sob a regência } \\
\text { do Maestro Abolicioaista, Tranquilino Bastos. Marchas e dobrados inurdaram as ruzs para ce- } \\
\text { lebrar o Decreto } \mathbb{N}^{*} 3353 \text {, mas conhecido como a Lei Aurea. A aboliçẫo formal da escravidão }\end{array}$ \\
\hline TEMPO DE REFLETIR & foi celetrada no Brasil. Mas o que veio em seguida? \\
\hline \multirow{5}{*}{ 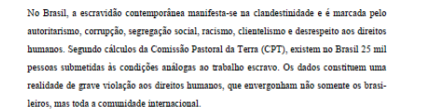 } & \multirow{5}{*}{ 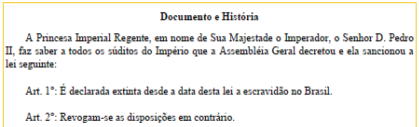 } \\
\hline & \\
\hline & \\
\hline & \\
\hline & \\
\hline 7 & 8 \\
\hline
\end{tabular}

\section{NOTAS}

${ }^{1}$ Os resultados deste artigo foram apresentados oralmente no Grupo de Discussão "Linguagens, tecnologias e produção de Materiais Didáticos em História” do III Encontro Estadual de Ensino de História, promovido pela Anpuh-BA em 24 a 26 ago. 2015; e na mesa "Os mestrados profissionais: desafios de consolidação" do II Encontro Nacional dos Mestrados Profissionais de História, UFG Catalão, de 29 set. a 2 out. 2015.

Artigo recebido em 4 de março de 2016. Aprovado em 23 de maio de 2016. 